Keywords: vascular endothelial growth factor receptor; tyrosine kinase inhibitors; approved; QTc interval prolongation; meta-analysis; cardiac toxicity

\title{
QTc interval prolongation with vascular endothelial growth factor receptor tyrosine kinase inhibitors
}

\author{
P Ghatalia ${ }^{1,5}$, Y Je ${ }^{2,5}$, M D Kaymakcalan ${ }^{3}$, G Sonpavde ${ }^{4,6}$ and T K Choueiri ${ }^{\star 3,6}$
}

${ }^{1}$ Department of Internal Medicine, University of Alabama at Birmingham (UAB), Birmingham, AL, USA; ${ }^{2}$ Department of Food and Nutrition, Kyung Hee University, Seoul, Republic of Korea; ${ }^{3}$ Dana Farber Cancer Institute and Harvard Medical School, 450 Brookline Avenue (DANA 1230), Boston, MA, 02215-5415 USA and ${ }^{4}$ Department of Internal Medicine, Section of Medical Oncology, UAB Medical CenterBirmingham, AL, USA

Background: Multi-targeted vascular endothelial growth factor receptor (VEGFR) tyrosine kinase inhibitors (TKIs) are known to cause cardiac toxicity, but the relative risk (RR) of QTc interval prolongation and serious arrhythmias associated with them are not reported.

Methods: We conducted a trial-level meta-analysis of randomised phase II and III trials comparing arms with and without a US Food and Drug Administration-approved VEGFR TKI (sunitinib, sorafenib, pazopanib, axitinib, vandetanib, cabozantinib, ponatinib and regorafenib). A total of 6548 patients from 18 trials were selected. Statistical analyses were conducted to calculate the summary incidence, RR and $95 \%$ Cls.

Results: The RR for all-grade and high-grade QTc prolongation for the TKI vs no TKI arms was $8.66(95 \% \mathrm{Cl} 4.92-15.2, P<0.001)$ and $2.69(95 \% \mathrm{Cl} 1.33-5.44, P=0.006)$, respectively, with most of the events being asymptomatic QTc prolongation. Respectively, $4.4 \%$ and $0.83 \%$ of patients exposed to VEGFR TKI had all-grade and high-grade QTc prolongation. On subgroup analysis, only sunitinib and vandetanib were associated with a statistically significant risk of QTc prolongation, with higher doses of vandetanib associated with a greater risk. The rate of serious arrhythmias including torsades de pointes did not seem to be higher with highgrade QTc prolongation. The risk of QTc prolongation was independent of the duration of therapy.

Conclusions: In the largest study to date, we show that VEGFR TKI can be associated with QTc prolongation. Although most cases were of low clinical significance, it is unclear whether the same applies to patients treated off clinical trials.

Several multi-targeted vascular endothelial growth factor receptor (VEGFR) tyrosine kinase inhibitors (TKI) have been approved by the US FDA including sunitinib, sorafenib, pazopanib, axitinib, vandetanib, cabozantinib, ponatinib and regorafenib. However, these agents may also target kinases that are essential for cardiac function. Multiple reports of QT prolongation in patients exposed to TKIs have emerged, some of which have been associated with ventricular arrhythmia and sudden death (Strevel et al, 2007; Schmidinger et al, 2008; Bello et al, 2009; Shah et al, 2013).
On the EKG, the QT interval is measured from the beginning of the QRS complex to the end of the $\mathrm{T}$ wave in the lead without prominent U waves (Zipes et al, 2005). Several formulae, the Bazett, Fridericia, Framingham and Hodges formulae, correct QT (QTc) for heart rate variability and an interval of $>450 \mathrm{~ms}$ for men and $460 \mathrm{~ms}$ for women is generally accepted as upper limit of normal (Bazett, 1920; Fridericia, 1920; Hodges et al, 1983; Sagie et al, 1992; Al-Khatib et al, 2003). Ventricular arrhythmias, particularly torsades de pointes (TdP), correlate with a QTc interval of > $500 \mathrm{~ms}$ (Bednar et al, 2001).

\footnotetext{
*Correspondence: Dr TK Choueiri; E-mail: toni_choueiri@dfci.harvard.edu

${ }^{5}$ These authors contributed equally to this work.

${ }^{6}$ These authors contributed equally to this work.
}

Received 4 August 2014; revised 15 September 2014; accepted 8 October 2014; published online 6 November 2014 
To balance the efficacy and safety of experimental drugs, two International Conference of Harmonisation (ICH) guidelines were released in 2005 that recommend preclinical and clinical studies to assess the effect of a drug on ventricular repolarisation. The preclinical evaluation consists of in vitro and in vivo testing of a drug's ability to block an important potassium ion channel involved in QTc prolongation, the human ether-a-go-go-related gene potassium ion channels $\left(\mathrm{hERG} \mathrm{K}^{+}\right.$) (Sanguinetti and Mitcheson, 2005). The clinical evaluation, called 'thorough QT/ QTc' study (TQT), recommends further trials using supratherapeutic doses in healthy volunteers by using a positive control and a placebo group. However, the feasibility of these evaluations in anticancer agents has been questioned as cancer agents cannot be studied in healthy volunteers, and placebo use in cancer patients may be controversial. For convenience, oncology trials have adapted alternative protocol designs other than the TQT study to address the question of drug-induced QTc prolongation (Strevel et al, 2007). Thus, the cardiac safety of all approved VEGFR TKIs has not been studied in the same manner. Given this, we performed a large trial-level meta-analysis of randomised clinical trials (RCTs) to evaluate and better quantify the impact of VEGFR TKIs on QTc interval prolongation and resulting serious arrhythmias.

\section{MATERIALS AND METHODS}

Selection of studies. An independent review of citations in the English language from PubMed/Medline from January 1966 to December 2013 was conducted. Key words included in the search were RCT, sunitinib, sorafenib, pazopanib, axitinib, vandetanib, cabozantinib, ponatinib and regorafenib. Abstracts and virtual meeting presentations from major conferences - American Society of Clinical Oncology (ASCO), European Society of Medical Oncology (ESMO) and American Association of Cancer Research (AACR) - were reviewed from January 2008 to April 2014. Updated manufacturer's package inserts and clinicaltrials.gov were also searched. Phase II and III RCTs comparing arms with and without a VEGFR TKI were selected. We excluded trials that contained a VEGF inhibitor or a TKI in all arms. Study quality was assessed by using the five-point Jadad ranking system (Jadad et al, 1996). Trials that did not list QTc prolongation as an adverse event in any arm were excluded.

Data extraction and clinical end points. Data abstraction was conducted independently by three investigators (PG, YJ and GS) according to the Preferred Reporting Items for Systematic Reviews and Meta-analyses (PRISMA) statement (Liberati et al, 2009). The variables extracted are shown in Table 1. The Common Terminology Criteria for Adverse Events (CTCAE) version 3.0, used by all trials, defines grade 1 QTc prologation as $450-470 \mathrm{~ms}$ and grade 2 QTc prolongation as $471-500 \mathrm{~ms}$ or $>60 \mathrm{~ms}$ change from baseline, both of which comprise low-grade QTc prolongation events. High-grade QTc prolongation consists of Grade 3 QTc prolongation defined as QTc $\geqslant 501 \mathrm{~ms}$ and grade 4 prolongation consisting of serious arrhythmias like TdP, polymorphic ventricular tachycardia or an arrhythmia with life-threatening signs or symptoms like CHF, hypotension, shock or syncope.

Statistical analysis. All statistical analyses were carried out by using Stata/SE version 12.0 software (Stata, College Station, TX, USA). For the calculation of incidence, the number of patients exposed to VEGFR TKI and those with all-grade and high-grade QTc prolongation were extracted from individual selected clinical trials. Using the extracted data, we also calculated relative risks (RRs) and 95\% CIs of all-grade and high-grade QTc prolongation in cancer patients assigned to VEGFR TKI $v s$ controls in the same trial. For trials reporting zero events in a treatment or control arm, we applied a classic half-integer continuity correction to calculate the incidences, RRs and their variances.

To compute a summary incidence and RR of all-grade and highgrade QTc prolongation, we combined study-specific estimates using both fixed effects models using the Mantel Haenszel method and random effects models using the DerSimonian and Laird method that considers both inter- and intra-study variations (DerSimonian and Laird, 1986). Statistical heterogeneity among trials included in the meta-analysis was assessed using the Cochran $Q$ statistic (Cochran, 1954), and the heterogeneity was quantified by calculating the $I^{2}$ statistic $\left.(100 \%)(Q-d f) / Q\right)$ that estimates the percentage of total variation due to heterogeneity between trials (Higgins et al, 2003). The assumption of homogeneity was considered invalid for $P<0.10$, and the results from the random effects model were presented when a substantial heterogeneity was found. When there is no evidence of heterogeneity, the random effects estimates are essentially the same as the fixed effects estimate.

Subset analyses were conducted to examine whether the RRs of all-grade QTc prolongation varied by the type of VEGFR TKI, phase of trial (phase 2 vs 3), EKG monitoring done at regular intervals in the trial (yes $v s$ no), duration of treatment (greater $v s$ lesser than the median duration of all trials) and only for vandetanib, $100 \mathrm{mg}$ vs $300 \mathrm{mg}$ dose. Finally, we evaluated publication bias for all-grade QTc prolongation through funnel plots (i.e., plots of trial results against precision) and with the Begg's (Begg and Mazumdar, 1994) and Egger's regression asymmetry tests (Egger et al, 1997). A two-tailed $P$-value of 0.05 was considered statistically significant.

\section{RESULTS}

Search results. Our search yielded a total of 94 potentially relevant RCTs comparing arms with or without a VEGFR TKI. Of these, 76 trials were excluded for not listing specific information on QTc prolongation as an adverse event in any of the arms. Figure 1 represents the selection process. The remaining 18 trials were considered highly relevant for the meta-analysis ( 9 phase II and 9 phase III trials) (Table 1) (Arnold et al, 2007; Heymach et al, 2007; Kim et al, 2009; Yang et al, 2009; Barrios et al, 2010; Herbst et al, 2010; Sternberg et al, 2010; deBoer, 2011; Kindler et al, 2011; Loriot et al, 2011; Hsu et al, 2012; Leboulleux et al, 2012; Lee et al, 2012; Van der Graaf et al, 2012; Wells et al, 2012; Ahn et al, 2013; Crown et al, 2013). The trials enrolled patients with pancreatic cancer $(n=1)$, breast cancer $(n=2)$, thyroid cancer $(n=2)$, colorectal cancer $(n=2)$, prostate cancer $(n=1)$, non-small-cell lung cancer $(n=5)$, small-cell lung cancer $(n=1)$, biliary tract cancer $(n=1)$, renal cell carcinoma (RCC; $n=1)$, soft-tissue sarcoma $(n=1)$ and hepatocellular cancer (HCC; $n=1$ ).

When examining by agent, sunitinib was investigated in 2 trials (910 patients), pazopanib in 2 trials (804 patients), vandetanib in 13 trials (4204 patients) and axitinib in 1 trial (630 patients). All trials evaluating axitinib, pazopanib and sunitinib used a dose of $5 \mathrm{mg}$ twice daily, $800 \mathrm{mg}$ daily and $37.5 \mathrm{mg}$ daily, respectively. The doses of vandetanib were $300 \mathrm{mg}$ daily in 6 trials (1715 patients) and $100 \mathrm{mg}$ daily in 2 trials (1912 patients). Five trials with vandetanib contained 2 separate arms with doses of $100 \mathrm{mg}$ (192 patients) and $300 \mathrm{mg}$ daily (193 patients). We combined these arms for the meta-analysis. Nine trials used a design of chemotherapy with or without TKI, 8 trials compared TKI alone with placebo and 1 trial compared bicalutamide alone or combined with TKI.

Trial quality. Randomised treatment allocation sequences were generated in all trials. Twelve trials were placebo controlled and double blinded (Arnold et al, 2007; Heymach et al, 2007; Yang et al, 2009; Herbst et al, 2010; Sternberg et al, 2010; deBoer, 2011; 


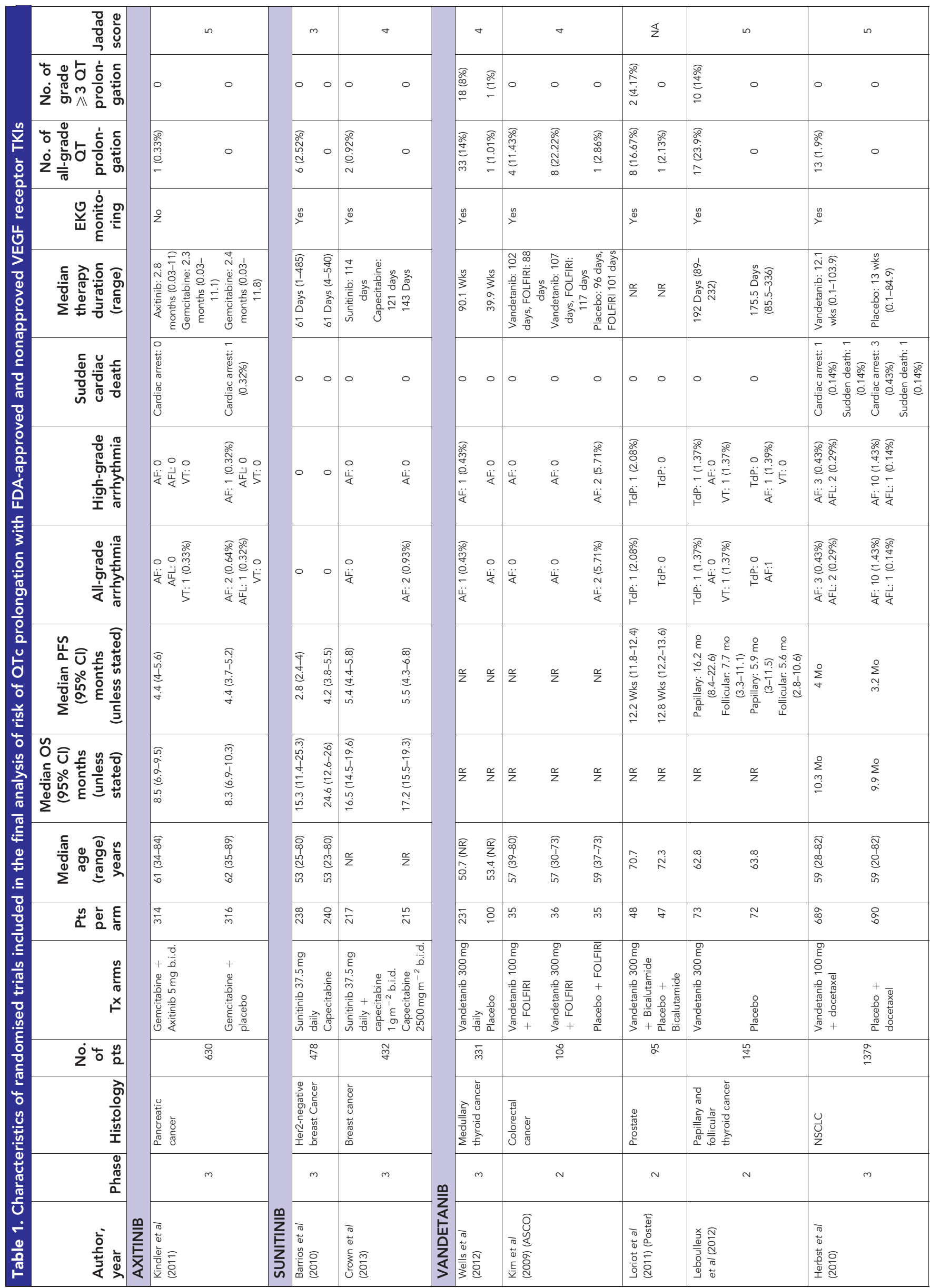




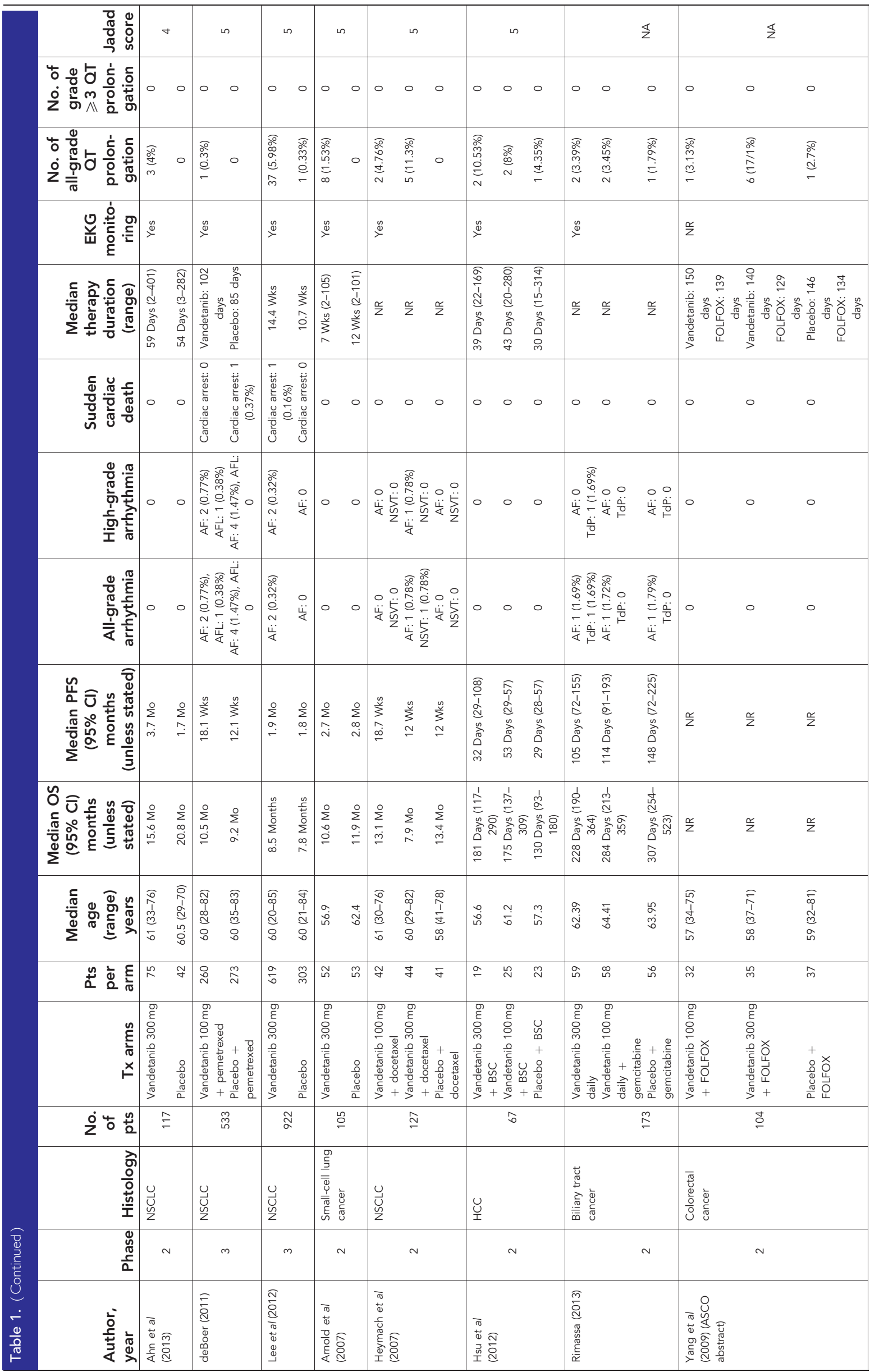




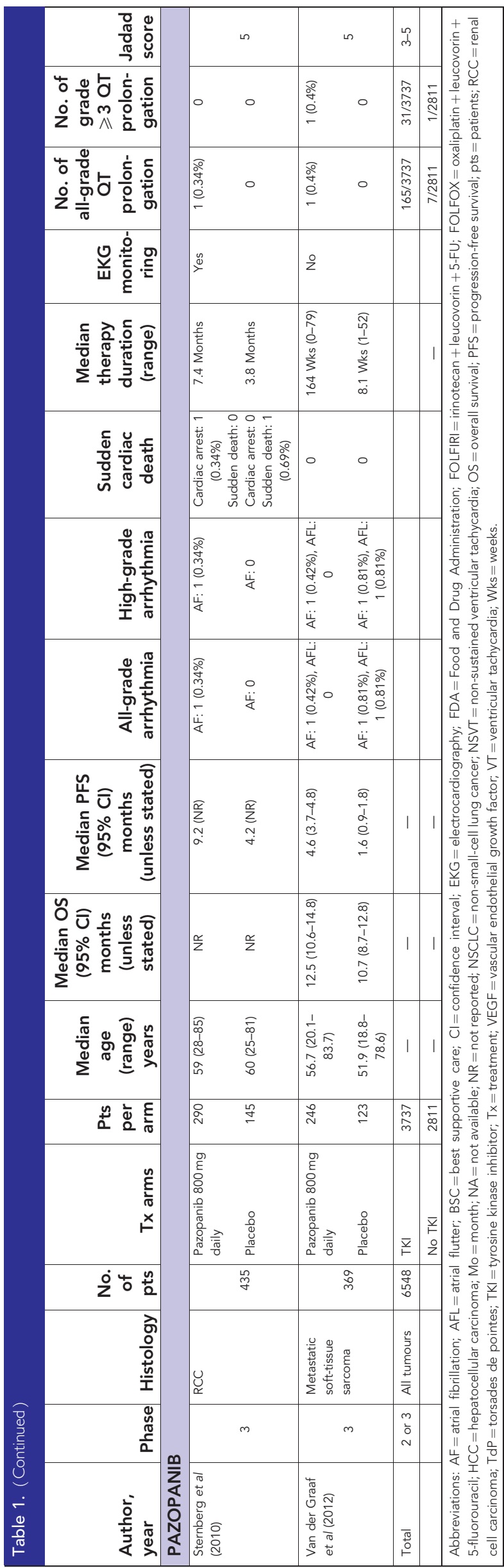

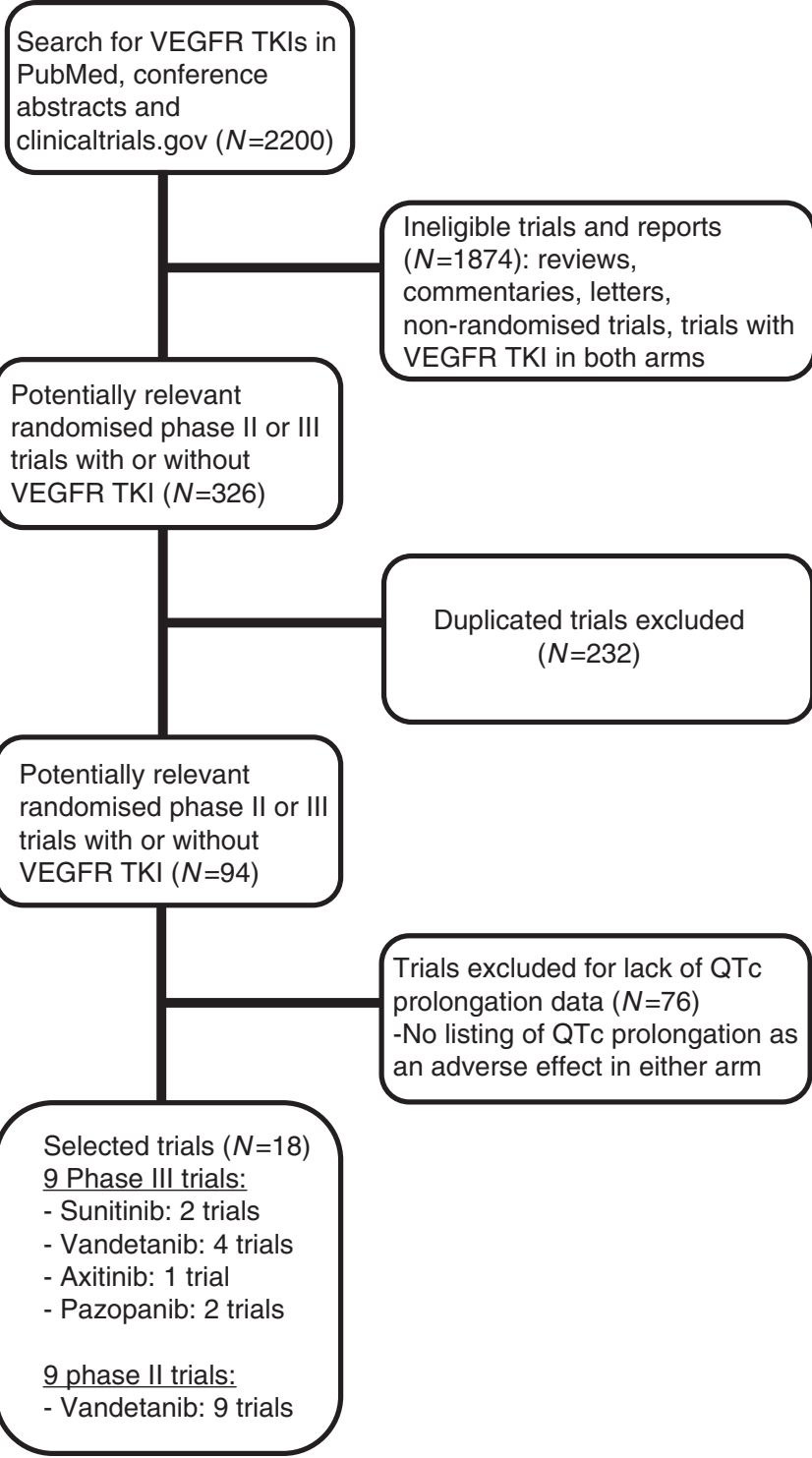

Figure 1. Selection process for trials included in the meta-analysis.

Kindler et al, 2011; Hsu et al, 2012; Leboulleux et al, 2012; Lee et al, 2012; Van der Graaf et al, 2012). Follow-up time was generally adequate for each trial and included a period of $\sim 2-4$ weeks after end of therapy on trial. The trials were all deemed of intermediate (Jadad score 3) or high quality (Jadad score 4-5).

Population characteristics. A total of 6548 patients were available for the meta-analysis: 3737 in the TKI group and 2811 in the control group. Patients were generally required to have an Eastern Cooperative Oncology Group (ECOG) performance status 0-1, adequate organ function and no brain metastasis. In one trial of axitinib (Kindler et al, 2011) and one trial of pazopanib (Van der Graaf et al, 2012), no EKG monitoring was performed, and in all other trials, EKG monitoring was performed at baseline and periodically throughout the study. We could not delineate if EKG monitoring was performed in one abstract presentation, as the report did not explicitly address it (NCT00753675). We assume here that EKG monitoring was not performed. Two trials excluded patients who were using concomitant QTc prolonging drugs (Arnold et al, 2007; Hsu et al, 2012) and three trials excluded patients with congenital or acquired QTc prolongation (Sternberg et al, 2010; Hsu et al, 2012; Van der Graaf et al, 2012). Trials invariably excluded patients with baseline QTc > $500 \mathrm{~ms}$. 
Relative risk of all-grade QTc prolongation events. All-grade QTc prolongation occurred in 165 of 3737 (4.41\%) patients receiving VEGFR TKIs. In the non-TKI group, all-grade QTc prolongation occurred in 7 of $2811(0.25 \%)$ patients. Subjects in the VEGFR TKI group were at a significantly higher risk for allgrade QTc prolongation than subjects in the non-TKI group $(\mathrm{RR}=8.66,95 \% \mathrm{CI} 4.92-15.2, P<0.001)$ with no evidence of heterogeneity $\left(Q=10.49, P=0.882, I^{2}=0.0 \%\right.$; Figure 2$)$. There was no evidence for publication bias for the RR of all-grade QTc interval prolongation by either the Begg's test $(P=0.06)$ or Egger's test $(P=0.61)$.

Relative risk of high-grade QTc prolongation events and highgrade arrhythmias. High-grade QTc prolongation occurred in 31 of $3737(0.83 \%)$ patients receiving VEGFR TKIs and in 1 of 2811 patients in the non-TKI group (0.03\%). Subjects in the VEGFR TKI group were at a greater risk of QTc prolongation than those in the non-TKI group $(\mathrm{RR}=2.69,95 \% \mathrm{CI} 1.33-5.44, P=0.006$; Figure 3$)$ with no significant heterogeneity $(Q=10.36, P=0.888$, $\left.I^{2}=0.0 \%\right)$. Reported high-grade/serious arrhythmias and sudden deaths in patients with QTc prolongation exposed to VEGFR TKI $(n=3737)$ and placebo $(n=2811)$ respectively included: atrial fibrillation (11 vs 19), atrial flutter (3vs 2), ventricular tachycardia ( 1 vs 0$)$, TdP ( 3 vs 0$)$, cardiac arrest ( $3 v s$ ) and sudden cardiac death (1 vs 2).

Subset analysis based on type of drug and trial. In the metaanalysis by drug type, we found a significantly increased risk of allgrade QTc interval prolongation among patients treated with vandetanib $(n=2432 ; \mathrm{RR}=9.63,95 \% \mathrm{CI} 5.14-18.0, P<0.001)$ and sunitinib $(n=455 ; \quad \mathrm{RR}=9.01,95 \% \quad \mathrm{CI} 1.15-70.7, \quad P=0.04)$, whereas no significant association was found in those treated with pazopanib $(n=536 ; \mathrm{RR}=1.51,95 \% \mathrm{CI} 0.16-4.41, P=0.72)$ or axitinib $(n=314$; RR $=3.02,95 \%$ CI $0.12-73.8, P=0.50$; Figure 3 ). Patients exposed to $300 \mathrm{mg}$ vandetanib $(n=1291)$ had a greater risk $(\mathrm{RR}=10.6,95 \%$ CI 5.31-21.2, $P<0.001)$ than patients exposed to $100 \mathrm{mg}$ vandetanib $(n=1141 ; \mathrm{RR}=4.83,95 \% \mathrm{CI}$
1.94-12, $P=0.001)$. There was no difference in QTc prolongation between phase II or III trials $(P=0.54)$.

Subset analysis based on EKG monitoring. Meta-analysis of trials that had EKG monitoring $(n=15)$ showed that the RR for all-grade QTc interval prolongation was 9.74 (95\% CI: 5.27-18.0, $P<0.001)$. The RR derived from the meta-analysis of trials without EKG monitoring $(n=3)$ was 3.05 (95\% CI: $0.68-13.75, P=0.15)$. However, there was no significant difference in RRs based on EKG monitoring $(P=0.30)$.

Subset analysis based on duration of treatment. Patients who may stay longer on a treatment arm may be more prone to develop events. To identify whether VEGFR TKI treatment duration influences the incidence of all-grade QTc interval prolongation, we compared the incidence of QTc interval prolongation among trials with short median duration of therapy (arbitrarily defined as less than the median duration of all trials) $v s$ those with long median duration of therapy (defined as greater than the median duration of all trials). Fifteen trials provided information on median duration of treatment, and there was no significant difference in incidences of QTc interval prolongation $(P=1.0$; Table 2). When the median treatment duration was included as a continuous variable in the meta-regression model, we found that there was no statistically significant difference in incidences of QTc interval prolongation $(P=0.55)$. For RRs by duration of treatment, no significant difference in trials with short $(\mathrm{RR}=11.3,95 \% \mathrm{CI}$ 4.4-29.0) vs long duration $(\mathrm{RR}=8.21,95 \% \mathrm{CI} 3.51-19.2)$ was found $(P=0.62)$.

\section{DISCUSSION}

Regulatory authorities have routinely required all new drugs to be characterised for their effect on cardiac repolarisation and QTc interval. The preclinical and clinical evaluations recommended by $\mathrm{ICH}$ to evaluate QTc interval effects of new drugs are often not

\begin{tabular}{|c|c|c|c|c|c|}
\hline & No. of eve & its/total & & & \\
\hline Source & $\frac{\text { VEGFR }}{\underline{\text { TKI }}}$ & Control & $\begin{array}{c}\text { Relative risk } \\
(95 \% \mathrm{Cl})\end{array}$ & & $P$-value \\
\hline Amold et al, 2007 & $8 / 52$ & $0 / 53$ & $17.3(1.03-292.6)$ & & 0.05 \\
\hline Heymach et al, 2007 & $7 / 86$ & $0 / 41$ & $7.24(0.42-123.8)$ & & 0.17 \\
\hline Kim et al, 2009 & $12 / 71$ & $1 / 35$ & $5.92(0.80-43.7)$ & $\frac{1}{2}$ & 0.08 \\
\hline Yang et al, 2009 & $7 / 67$ & $1 / 37$ & $3.87(0.49-30.2)$ & & 0.20 \\
\hline Barrios et al, 2010 & $6 / 238$ & $0 / 240$ & $13.1(0.74-231.4)$ & & 0.08 \\
\hline Herbst et al, 2010 & $13 / 689$ & $0 / 690$ & $27.0(1.61-454.0)$ & & 0.02 \\
\hline Stemberg et al, 2010 & $1 / 290$ & $0 / 145$ & $1.51(0.06-36.7)$ & i & 0.80 \\
\hline Kindler et al, 2011 & $1 / 314$ & $0 / 316$ & $3.02(0.12-73.8)$ & 1 & 0.50 \\
\hline De Boer et al, 2011 & $1 / 260$ & $0 / 273$ & $3.15(0.13-77.0)$ & & 0.48 \\
\hline Loriot et al, 2011 & $8 / 48$ & $1 / 47$ & $7.83(1.02-60.2)$ & & 0.05 \\
\hline Hsu et al, 2012 & $4 / 44$ & $1 / 23$ & $2.09(0.25-17.6)$ & $\rightarrow$ & 0.50 \\
\hline Leboulleux et al, 2012 & $17 / 73$ & $0 / 72$ & $34.5(2.12-563.5)$ & & 0.01 \\
\hline Lee et al, 2012 & $37 / 619$ & $1 / 303$ & $18.1(2.50-131.4)$ & $t$ & 0.004 \\
\hline Van der Graaf et al, 2012 & $1 / 246$ & $0 / 123$ & $1.51(0.06-36.7)$ & & 0.80 \\
\hline Wells et al, 2012 & $33 / 231$ & $1 / 100$ & $14.3(1.98-103.0)$ & & 0.008 \\
\hline Ahn et al, 2013 & $3 / 75$ & $0 / 42$ & $3.96(0.21-74.9)$ & i & 0.36 \\
\hline Crown et al, 2013 & $2 / 217$ & $0 / 215$ & $4.95(0.24-102.6)$ & 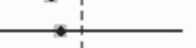 & 0.30 \\
\hline Rimassa et al, 2013 & $4 / 117$ & $1 / 56$ & $1.91(0.22-16.7)$ & 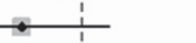 & 0.56 \\
\hline Overall & $165 / 3737$ & $7 / 2811$ & $8.66(4.92-15.2)$ & $>$ & $<0.001$ \\
\hline Test for heterogeneity: $Q=$ & $10.49, P=0$ & $2, T=0$ & & & \\
\hline & & & & $\begin{array}{lll}5 & 10 \quad 50\end{array}$ & \\
\hline & & & & risk $(95 \% \mathrm{Cl})$ & \\
\hline
\end{tabular}

Figure 2. VEGFR TKIs were associated with a significantly higher risk for all-grade QTc interval prolongation compared with no TKIs $(R R=8.75$, $P<0.001,95 \% \mathrm{Cl} 4.97-15.4)$. There was no evidence of heterogeneity $\left(Q=10.55, P=0.879, P^{2}=0.0 \%\right)$. The size of the squares indicates the weight of the study, and the diamond indicates the summary RR. 


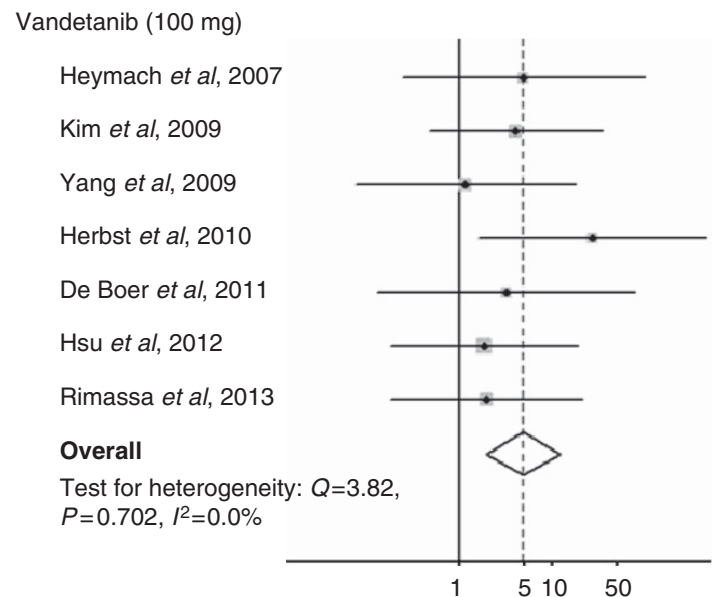

Vandetanib (300 mg)

Amold et al, 2007

Heymach et al, 2007

Kim et al, 2009

Yang et al, 2009

Loriot et al, 2011

Hsu et al, 2012

Leboulleux et al, 2012

Lee et al, 2012

Wells et al, 2012

Ahn et al, 2013

Rimassa et al, 2013

Overall

Test for heterogeneity: $Q=5.59$, $P=0.849, I^{2}=0.0 \%$
Relative risk

$(95 \% \mathrm{Cl})$

$P$-value

$4.88(0.24-98.7) \quad 0.30$

$4.00(0.47-34.0) \quad 0.20$

$1.16(0.08-17.7) \quad 0.92$

$27.0(1.61-453.9) \quad 0.02$

$3.15(0.13-77.0) \quad 0.48$

$1.84(0.18-19.0) \quad 0.61$

$1.93(0.18-20.7) \quad 0.59$

$4.83(1.94-12.0) \quad 0.001$

$\begin{array}{ll}17.3(1.03-292.6) & 0.05 \\ 10.3(0.59-180.1) & 0.11 \\ 7.78(1.03-59.0) & 0.05 \\ 6.34(0.80-50.1) & 0.08 \\ 7.83(1.02-60.2) & 0.05 \\ 2.42(0.24-24.7) & 0.46 \\ 34.5(2.12-563.5) & 0.01 \\ 18.11(2.50-131.4) & 0.004 \\ 14.3(1.98-103.0) & 0.008 \\ 3.96(0.21-74.9) & 0.36 \\ 1.90(0.18-20.4) & 0.60 \\ 10.6(5.31-21.2) & <0.001\end{array}$

$17.3(1.03-292.6) \quad 0.05$

0.11

.05

.46

01

004

.008

0.60

$<0.001$

indicates the weight of the study, and the diamond indicates the summary RR.

Table 2. Incidence and relative risk of all-grade QTc interval prolongation associated with VEGFR TKIs stratified by drug

\begin{tabular}{|c|c|c|c|c|c|c|}
\hline \multirow[b]{2}{*}{ Type of drug } & \multirow[b]{2}{*}{$\begin{array}{l}\text { Number of } \\
\text { studies }\end{array}$} & \multicolumn{5}{|c|}{ Incidence } \\
\hline & & $\begin{array}{c}\text { Number of events/sample size } \\
\text { TKI; Control }\end{array}$ & $\begin{array}{l}\text { VEGFR TKIs } \\
\%(95 \% \mathrm{Cl})\end{array}$ & $\begin{array}{c}\text { Control } \\
\%(95 \% \mathrm{Cl})\end{array}$ & $\begin{array}{l}\text { Relative risk } \\
(95 \% \mathrm{Cl})\end{array}$ & $P$-value \\
\hline Overall & 18 & $165 / 3737 ; 7 / 2811$ & $4.9(2.9-7.9)$ & $0.9(0.5-1.5)$ & $8.66(4.92-15.2)$ & $<0.001$ \\
\hline Vandetanib & 13 & $154 / 2432 ; 7 / 1772$ & $8.0(5.0-12.7)$ & $1.2(0.6-2.2)$ & $9.63(5.14-18.0)$ & $<0.001$ \\
\hline $100 \mathrm{mg}$ & 7 & $25 / 1141 ; 4 / 1155$ & $3.6(1.6-7.5)$ & $1.5(0.6-3.3)$ & $4.83(1.94-12.0)$ & 0.001 \\
\hline $300 \mathrm{mg}$ & 11 & $129 / 1291 ; 7 / 809$ & 12.2 (8.3-17.7) & $1.5(0.8-2.8)$ & $10.6(5.31-21.2)$ & $<0.001$ \\
\hline Sunitinib & 2 & $8 / 455 ; 0 / 455$ & $2.0(1.0-3.8)$ & $0.2(0.0-1.6)$ & $9.01(1.15-70.7)$ & 0.04 \\
\hline Pazopanib & 2 & $2 / 536 ; 0 / 268$ & $0.4(0.1-1.5)$ & $0.4(0.0-2.6)$ & $1.51(0.16-14.4)$ & 0.72 \\
\hline Axitinib ${ }^{a}$ & 1 & $1 / 314 ; 0 / 316$ & $0.3(0.04-2.2)$ & $0.2(0.0-2.4)$ & $3.02(0.12-73.8)$ & 0.50 \\
\hline
\end{tabular}

feasible for oncologic drugs. This prompted us to perform the first and largest study evaluating the risk of QTc prolongation and serious arrhythmias associated with all US FDA-approved VEGFR TKIs as of December 2013. In this analysis of 6548 patients, 18 randomised phase II and III trials using approved VEGFR TKIs (sunitinib, sorafenib, pazopanib, axitinib, vandetanib, cabozantinib, ponatinib and regorafenib) were included. We did not include phase I trials in our meta-analysis as they are nonrandomised and include a wide range of drug doses. In addition, we did not include trials containing a VEGFR blocker or TKI in all arms. We observed a significant 8.66 -fold increase (95\% CI 4.92-15.2, $P<0.001$ ) in the risk of all grades of QTc prolongation with VEGFR TKIs compared 
with controls not receiving TKIs. The risk of high-grade QTc prolongation was also significant $(\mathrm{RR}=2.69,95 \% \mathrm{CI} 1.33-5.44$, $P=0.006)$. Interestingly, longer duration of therapy did not appear to significantly increase the RR, suggesting that the risk may be stable over time and early detection may play a clinical role in preventing fatal outcomes. In the study by Bello et al (2009) evaluating the pharmacokinetics of sunitinib, the time at which the maximum change in QTc interval occurred did not correlate well with the time at which the concentration of the drug was maximum, indicating that there may be a lag time for QTc prolongation. However, we have not been able to detect pharmacokinetic studies where the correlation between the duration of drug exposure and QTc prolongation is studied.

In the preclinical and phase I studies for VEGFR TKIs, sunitinib and vandetanib were found to be at a higher risk for QTc prolongation than other TKIs. In the pivotal clinical trial for vandetanib $(n=331)$ (Wells et al, 2012) the mean increase in QTc interval was $35 \mathrm{~ms}$ with an increase of $>60 \mathrm{~ms}$ in $35.5 \%$ of the patients (FDA). Bello et al (2009) reported, in their TQT evaluation of sunitinib, a dose-dependent increase in QTc with mean maximum increase from $9.6 \mathrm{~ms}$ at therapeutic concentrations and $15.4 \mathrm{~ms}$ at supratherapeutic concentrations $(n=48)$. These data are consistent with our study - the RR of QTc prolongation for vandetanib $(\mathrm{RR}=9.63,95 \% \mathrm{CI} 5.21-18.3, P<0.001)$ and sunitinib $(\mathrm{RR}=9.01,95 \%$ CI $1.15-70.7, P=0.036)$. Moreover, patients exposed to $300 \mathrm{mg}$ dose of vandetanib were at a higher risk of QTc prolongation than those exposed to $100 \mathrm{mg}$ dose. The fact that the risk for QTc prolongation may be concentration dependent becomes increasingly important when taking into consideration drug interactions caused by concomitant medications that can increase VEGFR TKI exposure. As many VEGFR TKIs are metabolised by cytochrome P450 (CYP) 3A4A, there is a significant potential for potent CYP3A4 inhibitors to increase VEGFR TKI concentration and toxicities including QTc prolongation. A drug interaction study on TKIs done by the Mayo Clinic reported co-prescribing rates of $24-74 \%$ with concomitant medications that may increase TKI toxicity (Bowlin et al, 2013). Monitoring for potential interacting medications by a physician or a pharmacist is vital to safely prescribe VEGF TKIs to patients in the community.

Although the other TKIs, pazopanib and axitinib, did not demonstrate statistically significant increases in RRs, this may be limited by power - two trials evaluating pazopanib (totalling 804 patients) and a single trial evaluating axitinib (including 630 patients). Moreover, for the single axitinib trial, no EKG monitoring was performed, and similarly for pazopanib, for which only one of two trials had EKG monitoring. Houk et al (2008) reported a small effect of axitinib on QTc interval ( $<10 \mathrm{~ms})$ $(n=32)$ and Heath et al (2013) found no significant concentration-dependent effect of pazopanib on QTc interval when randomising patients to pazopanib or moxifloxacin $(n=96)$. We did not find any eligible trials of sorafenib, regorafenib, ponatinib or cabozantinib reporting QTc prolongation. On reviewing the effects of the anti-angiogenic monoclonal antibody bevacizumab on QTc, no RCTs report QTc prolongation, suggesting that the mechanism may be unrelated to inhibiting the VEGF signalling axis. Moreover, an RCT for aflibercept, a more promiscuous recombinant human fusion protein that binds to VEGF-A and VEGF-B, reported a small increase in QTcF (maximum mean increase of $8.4 \mathrm{~ms}$ ) (Maison-Blanche et al, 2013).

Mechanistically, drug-induced QTc interval prolongation is thought to be directly caused by a drug's three-dimensional molecular structure interacting with myocardial hERG $\mathrm{K}^{+}$ channels that results in impeded electrical flow and delayed impulse conduction (Sanguinetti and Mitcheson, 2005). Preclinical studies of sunitinib and vandetanib, but not other VEGFR TKIs, showed that they interact with hERG $\mathrm{K}^{+}$(Health Canada
Summary Basis of Decision, 2014a,b). Another proposed mechanism of QTc prolongation that is not tested in preclinical studies is inhibition of hERG $\mathrm{K}^{+}$channel protein trafficking. Interference with the process of taking the hERG channel chaperone proteins leaving the endoplasmic reticulum towards the plasma membrane leads (potentially through drug-induced misfolding or drug-drug alteration of protein/chaperone interactions) to reduced hERG $\mathrm{K}+$ current. (Obers et al, 2010; Dennis et al, 2012), thereby affecting cardiac repolarisation. Baseline cardiovascular status and electrolyte imbalances also contribute to QTc prolongation. In addition, concomitant medications with their own potential to prolong QTc interval can additively impact the risk caused by VEGKR TKIs. Particularly important are the medications that are commonly needed in the oncology setting for symptom management: antiemetics such as ondansetron, palosetron, granisetron, prochlorperazine, and olanzapine, analgesics such as methadone and antidepressants such as citalopram, escitalopram, venlafaxine, sertraline and mirtazepine. The Arizona Center for Education and Research on Therapeutics has created a comprehensive list of medications and has classified them according to their potential to prolong QTc (https://www.crediblemeds.org/). Clinicians can refer to this database to identify concomitant medications with a potential to prolong QTc when initiating patients on VEGFR TKIs.

The disproportionate number of trials with vandetanib in our meta-analysis (13 out of 18 trials) may reflect stricter EKG monitoring in these patients. Indeed, on reviewing all available published RCTs in PubMed with or without TKI, we found that EKG monitoring was performed at regular intervals in all but one vandetanib trial, $50 \%$ of sunitinib trials, $50 \%$ of pazopanib trials, $11 \%$ of sorafenib trials and none of the axitinib trials. Few eligible RCTs for regorafenib $(n=2)$, cabozantinib $(n=1)$ and ponatinib $(n=0)$ were available, and all of these had monitored EKG but did not report QTc prolongation in any arm. The lack of routine QTc monitoring in patients receiving sorafenib, axitinib and pazopanib may be because of the fact that significant QTc prolongation was not reported in the preclinical and phase I studies for these drugs (Tolcher et al, 2011; Pithavala et al, 2012; Heath et al, 2013). Confounding variables at the patient level, such as comorbidities, age and previous chemotherapeutic exposure, could not be incorporated into the analysis. Nevertheless, meta-analyses are considered reasonable to study rare events that cannot be comprehensively studied in prospective trials. Studies suggest that trial-level and patient-level meta-analyses yield similar results (Landry et al, 2010).

It is important to note that the rate of serious arrhythmias, and especially TdP, did not seem to be elevated even in the group of patients who developed high-grade QTc prolongation. However, this does not imply the lack of correlation between QTc prolongation and serious arrhythmias. It should be noted that most trials in our study had EKG monitoring or/and frequent visits, and included relatively healthy populations with stable cardiac function. This may not necessarily apply to the general population. Unsurprisingly, the rates of treatment modifications because of adverse events tend to be higher in community practice (Feinberg et al, 2012; Oh et al, 2014) than what is generally reported in clinical trials. Furthermore, recent data suggest that the number of patients who are ineligible for clinical trials is substantial and their outcomes in terms of survival and time on therapy are inferior (Choueiri et al, 2010; Heng et al, 2014), likely because of the fact that registered clinical trials have strict eligibility criteria. In this regard, we recommend that routine EKG monitoring should be performed in patients receiving VEGFR TKIs. This has become a practice in patients receiving vandetanib and sunitinib, but may be extended to patients receiving other VEGFR TKIs as well.

In conclusion, the use of small-molecule VEGFR TKIs is associated with an increase in the RR and incidence of developing all-grade and high-grade QTc prolongation in a broad range of 
malignancies. The QTc prolongation was mostly asymptomatic with rare arrhythmias and death. Vandetanib and sunitinib may be particularly associated with a significantly increased risk, with higher doses associated with a greater risk. It is necessary to identify cardiac risk factors, evaluate QTc interval (at baseline and periodically), minimise the use of concomitant QTc prolonging medications, involve a specialised oncology clinical pharmacist early and correct electrolyte abnormalities (hypomagnesaemia, hypokalaemia, hypocalcaemia) in patients on VEGFR TKIs.

\section{CONFLICT OF INTEREST}

TKC is on the advisory board of GSK, Pfizer, Bayer, and obtained a Research grant from Pfizer. The remaining authors declare no conflict of interest.

\section{REFERENCES}

Ahn JS, Lee KH, Sun JM, Park K, Kang ES, Cho EK, Lee DH, Kim SW, Lee GW, Kang JH, Lee JS, Lee JW, Ahn MJ (2013) A randomized, phase II study of vandetanib maintenance for advanced or metastatic non-smallcell lung cancer following first-line platinum-doublet chemotherapy. Lung Cancer 82(3): 455-460.

Al-Khatib SM, LaPointe NM, Kramer JM, Califf RM (2003) What clinicians should know about the QT interval. JAMA 289(16): 2120-2127.

Arnold AM, Seymour L, Smylie M, Ding K, Ung Y, Findlay B, Lee CW, Djurfeldt M, Whitehead M, Ellis P, Goss G, Chan A, Meharchand J, Alam Y, Gregg R, Butts C, Langmuir P, Shepherd F. National Cancer Institute of Canada Clinical Trials Group Study BR.20 (2007) Phase II study of vandetanib or placebo in small-cell lung cancer patients after complete or partial response to induction chemotherapy with or without radiation therapy: National Cancer Institute of Canada Clinical Trials Group Study BR.20. J Clin Oncol 25(27): 4278-4284.

Barrios CH, Liu MC, Lee SC, Vanlemmens L, Ferrero JM, Tabei T, Pivot X, Iwata H, Aogi K, Lugo-Quintana R, Harbeck N, Brickman MJ, Zhang K, Kern KA, Martin M (2010) Phase III randomized trial of sunitinib versus capecitabine in patients with previously treated HER2-negative advanced breast cancer. Breast Cancer Res Treat 121(1): 121-131.

Bazett HC (1920) An analysis of the time relations to electrocardiograms. Heart 7: 353-370.

Bednar MM, Harrigan EP, Anziano RJ, Camm AJ, Ruskin JN (2001) The QT interval. Prog Cardiovasc Dis 43(5 Suppl 1): 1-45.

Begg CB, Mazumdar M (1994) Operating characteristics of a rank correlation test for publication bias. Biometrics 50(4): 1088-1101.

Bello CL, Mulay M, Huang X, Patyna S, Dinolfo M, Levine S, Van Vugt A, Toh M, Baum C, Rosen L (2009) Electrocardiographic characterization of the QTc interval in patients with advanced solid tumors: pharmacokinetic- pharmacodynamic evaluation of sunitinib. Clin Cancer Res 15(22): 7045-7052.

Bowlin SJ, Xia F, Wang W, Robinson KD, Stanek EJ (2013) Twelve-month frequency of drug-metabolizing enzyme and transporter-based drug-drug interaction potential in patients receiving oral enzyme-targeted kinase inhibitor antineoplastic agents. Mayo Clin Proc 88(2): 139-148.

Choueiri TK, Duh MS, Clement J, Brick AJ, Rogers MJ, Kwabi C, Shah K, Percy AG, Antràs L, Jayawant SS, Chen K, Wang ST, Luka A, Neary MP, McDermott D, Oh WK (2010) Angiogenesis inhibitor therapies for metastatic renal cell carcinoma: effectiveness, safety and treatment patterns in clinical practice-based on medical chart review. BJU Int 105(9): $1247-1254$.

Cochran W (1954) The combination of estimates from different experiments. Biometrics 10: 101-129.

Crown JP, Diéras V, Staroslawska E, Yardley DA, Bachelot T, Davidson N, Wildiers H, Fasching PA, Capitain O, Ramos M, Greil R, Cognetti F, Fountzilas G, Blasinska-Morawiec M, Liedtke C, Kreienberg R, Miller WH, Tassell V, Huang X, Paolini J, Kern KA, Romieu G (2013) Phase III trial of sunitinib in combination with capecitabine versus capecitabine monotherapy for the treatment of patients with pretreated metastatic breast cancer. J Clin Oncol 31(23): 2870-2878.
deBoer R (2011) Vandetanib plus pemetrexed for the second-line treatment of advanced non-small-cell lung cancer: a randomized, double-blind phase III trial. J Clin Oncol 29(8): 1067-1074.

Dennis AT, Wang L, Wan H, Nassal D, Deschenes I, Ficker E (2012) Molecular determinants of pentamidine-induced hERG trafficking inhibition. Mol Pharmacol 81(2): 198-209.

DerSimonian R, Laird N (1986) Meta-analysis in clinical trials. Control Clin Trials 7(3): 177-188.

Egger M, Davey Smith G, Schneider M, Minder C (1997) Bias in meta-analysis detected by a simple, graphical test. BMJ 315(7109): 629-634.

Feinberg BA, Jolly P, Wang ST, Fortner B, Scott J, Gilmore J, Neary MP, Duh MS (2012) Safety and treatment patterns of angiogenesis inhibitors in patients with metastatic renal cell carcinoma: evidence from US community oncology clinics. Med Oncol 29(2): 786-794.

Fridericia LS (1920) The duration of systole in electrocardiogram in normal humans and in patients with heart disease. Acta Med Scan 53: 469-486.

Heath EI, Infante J, Lewis LD, Luu T, Stephenson J, Tan AR, Kasubhai S, LoRusso P, Ma B, Suttle AB, Kleha JF, Ball HA, Dar MM (2013) A randomized, double-blind, placebo-controlled study to evaluate the effect of repeated oral doses of pazopanib on cardiac conduction in patients with solid tumors. Cancer Chemother Pharmacol 71(3): 565-573.

Health Canada (2014a) Summary Basis of Decision (SBD): Caprelsa. Available at: http://www.hc-sc.gc.ca/dhp-mps/prodpharma/sbd-smd/drug-med/ sbd_smd_2012_caprelsa_126822-eng.php (accessed 13 April 2014).

Health Canada (2014b) Summary Basis of Decision (SBD): Sutent. Available at: http://www.hc-sc.gc.ca/dhp-mps/prodpharma/sbd-smd/drug-med/ sbd_smd_2007_sutent_101319-eng.php (accessed 13 April 2014).

Heng DY, Choueiri TK, Rini BI, Lee J, Yuasa T, Pal SK, Srinivas S, Bjarnason GA, Knox JJ, Mackenzie M, Vaishampayan UN, Tan MH, Rha SY, Donskov F, Agarwal N, Kollmannsberger C, North S, Wood LA (2014) Outcomes of patients with metastatic renal cell carcinoma that do not meet eligibility criteria for clinical trials. Ann Oncol 25(1): 149-154.

Herbst RS, Sun Y, Eberhardt WE, Germonpré P, Saijo N, Zhou C, Wang J, Li L, Kabbinavar F, Ichinose Y, Qin S, Zhang L, Biesma B, Heymach JV, Langmuir P, Kennedy SJ, Tada H, Johnson BE (2010) Vandetanib plus docetaxel versus docetaxel as second-line treatment for patients with advanced non-small-cell lung cancer (ZODIAC): a double-blind, randomised, phase 3 trial. Lancet Oncol 11(7): 619-626.

Heymach JV, Johnson BE, Prager D, Csada E, Roubec J, Pesek M, Spásová I, Belani CP, Bodrogi I, Gadgeel S, Kennedy SJ, Hou J, Herbst RS (2007) Randomized, placebo-controlled phase II study of vandetanib plus docetaxel in previously treated non small-cell lung cancer. J Clin Oncol 25(27): 4270-4277.

Higgins JP, Thompson SG, Deeks JJ, Altman DG (2003) Measuring inconsistency in meta-analyses. Bmj 327(7414): 557-560.

Hodges M, Salerno D, Erlien D (1983) Bazett's QT correction reviewed: evidence that a linear correction for heart rate is better. J Am Coll Cardiol 1: 694 .

Houk BE, Sarapa N, Pithavala YK (2008) Effect of axitinib (AG-013736) concentration on QT interval after administration alone and in combination with ketoconazole in healthy volunteers (abstract PII-36). Presented at the 109th Annual Meeting of the American Society for Clinical Pharmacology and Therapeutics.

Hsu C, Yang TS, Huo TI, Hsieh RK, Yu CW, Hwang WS, Hsieh TY, Huang WT, Chao Y, Meng R, Cheng AL (2012) Vandetanib in patients with inoperable hepatocellular carcinoma: a phase II, randomized, double-blind, placebocontrolled study. J Hepatol 56(5): 1097-1103.

Jadad AR, Moore RA, Carroll D, Jenkinson C, Reynolds DJ, Gavaghan DJ, McQuay HJ (1996) Assessing the quality of reports of randomized clinical trials: is blinding necessary? Control Clin Trials 17(1): 1-12.

Kim T, Saunder M, Salazar R, Guren T, Sorbye H, Samuel L, Sanders N, Pover S, Im S (2009) A randomized, double-blind, placebo-controlled phase II study of vandetanib plus FOLFIRI in patients with advanced colorectal cancer (CRC). ASCO Gastrointestinal Cancers Symposium, abstract 188.

Kindler HL, Ioka T, Richel DJ, Bennouna J, Létourneau R, Okusaka T, Funakoshi A, Furuse J, Park YS, Ohkawa S, Springett GM, Wasan HS, Trask PC, Bycott P, Ricart AD, Kim S, Van Cutsem E (2011) Axitinib plus gemcitabine versus placebo plus gemcitabine in patients with advanced pancreatic adenocarcinoma: a double-blind randomised phase 3 study. Lancet Oncol 12(3): 256-262.

Landry J, Catalano PJ, Staley C, Harris W, Hoffman J, Talamonti M, Xu N, Cooper H, Benson AB (2010) Randomized phase II study of gemcitabine plus radiotherapy versus gemcitabine, 5 -fluorouracil, and cisplatin followed by 
radiotherapy and 5-fluorouracil for patients with locally advanced, potentially resectable pancreatic adenocarcinoma. J Surg Oncol 101(7): 587-592.

Leboulleux S, Bastholt L, Krause T, de la Fouchardiere C, Tennvall J, Awada A, Gómez JM, Bonichon F, Leenhardt L, Soufflet C, Licour M, Schlumberger MJ (2012) Vandetanib in locally advanced or metastatic differentiated thyroid cancer: a randomised, double-blind, phase 2 trial. Lancet Oncol 13(9): 897-905.

Lee JS, Hirsh V, Park K, Qin S, Blajman CR, Perng RP, Chen YM, Emerson L, Langmuir P, Manegold C (2012) Vandetanib versus placebo in patients with advanced non-small-cell lung cancer after prior therapy with an epidermal growth factor receptor tyrosine kinase inhibitor: a randomized, double-blind phase III trial (ZEPHYR). J Clin Oncol 30(10): 1114-1121.

Liberati A, Altman DG, Tetzlaff J, Mulrow C, Gøtzsche PC, Ioannidis JP, Clarke M, Devereaux PJ, Kleijnen J, Moher D (2009) The PRISMA statement for reporting systematic reviews and meta-analyses of studies that evaluate health care interventions: explanation and elaboration. $J$ Clin Epidemiol 62(10): e1-34.

Loriot Y, Houede N, Le Moulec S, Hennequin C, Eymard JC, Beuzebec P, Oudard S, Culine S, Tisseron A, Fizazi K (2011) Bicalutamide in combination with vandetanib or placebo in patients with castrationrefractory metastatic prostate cancer without any clinical symptom related to disease progression - a randomized, double-blind phase II trial. Eur J Cancer 47: S500 poster 7051.

Maison-Blanche P, Vermorken JB, Goksel T, Machiels JP, Agarwala S, Rottey S, Daugaard G, Volovat C, Scheulen M, Sengeløv L, Grecea D, Eniu A, Jäger E, Meiri E, Cascinu S, Strumberg D, Demir G, Clemens M, Pinotti G, Nardi M, Guthrie T, Boelle E, Magherini E (2013) A randomized, double-blind, placebo-controlled study to assess QTc interval prolongation of standard dose aflibercept in cancer patients treated with docetaxel. J Cardiovasc Pharmacol 61(6): 495-504.

Obers S, Staudacher I, Ficker E, Dennis A, Koschny R, Erdal H, Bloehs R, Kisselbach J, Karle CA, Schweizer PA, Katus HA, Thomas D (2010) Multiple mechanisms of hERG liability: $\mathrm{K}+$ current inhibition, disruption of protein trafficking, and apoptosis induced by amoxapine. Naunyn Schmiedebergs Arch Pharmacol 381(5): 385-400.

Oh WK, McDermott D, Porta C, Levy A, Elaidi R, Scotte F, Hawkins R, Castellano D, Bellmunt J, Rha SY, Sun JM, Nathan P, Feinberg BA, Scott J, McDermott R, Ahn JH, Wagstaff J, Chang YH, Ou YC, Donnellan P, Huang CY, McCaffrey J, Chiang PH, Chuang CK, Korves C, Neary MP, Diaz JR, Mehmud F, Duh MS (2014) Angiogenesis inhibitor therapies for advanced renal cell carcinoma: toxicity and treatment patterns in clinical practice from a global medical chart review. Int $J$ Oncol 44(1): 5-16.

Pithavala YK, Tong W, Mount J, Rahavendran SV, Garrett M, Hee B, Selaru P, Sarapa N, Klamerus KJ (2012) Effect of ketoconazole on the pharmacokinetics of axitinib in healthy volunteers. Invest New Drugs 30(1): 273-281.

Rimassa L (2013) Vandetanib Gemcitabine or placebo plus Gemcitabine or Vandetanib monotherapy in advanced biliary tract cancer (VANGOGH). http://clinicaltrials.gov/ct2/show/record/NCT00753675 (accessed October 2014).
Sagie A, Larson MG, Goldberg RJ, Bengtson JR, Levy D (1992) An improved method for adjusting the QT interval for heart rate (the Framingham Heart Study). Am J Cardiol 70: 797-801.

Sanguinetti MC, Mitcheson JS (2005) Predicting drug-hERG channel interactions that cause acquired long QT syndrome. Trends Pharmacol Sci 26(3): 119-124.

Schmidinger M, Zielinski CC, Vogl UM, Bojic A, Bojic M, Schukro C, Ruhsam M, Hejna M, Schmidinger H (2008) Cardiac toxicity of sunitinib and sorafenib in patients with metastatic renal cell carcinoma. J Clin Oncol 26(32): 5204-5212.

Shah RR, Morganroth J, Shah DR (2013) Cardiovascular safety of tyrosine kinase inhibitors: with a special focus on cardiac repolarisation (QT interval). Drug Saf 36(5): 295-316.

Sternberg CN, Davis ID, Mardiak J, Szczylik C, Lee E, Wagstaff J, Barrios CH, Salman P, Gladkov OA, Kavina A, Zarbá JJ, Chen M, McCann L, Pandite L, Roychowdhury DF, Hawkins RE (2010) Pazopanib in locally advanced or metastatic renal cell carcinoma: results of a randomized phase III trial. J Clin Oncol 28(6): 1061-1068.

Strevel EL, Ing DJ, Siu LL (2007) Molecularly targeted oncology therapeutics and prolongation of the QT interval. J Clin Oncol 25(22): 3362-3371.

Tolcher AW, Appleman LJ, Shapiro GI, Mita AC, Cihon F, Mazzu A, Sundaresan PR (2011) A phase I open-label study evaluating the cardiovascular safety of sorafenib in patients with advanced cancer. Cancer Chemother Pharmacol 67(4): 751-764.

Van der Graaf WT, Blay JY, Chawla SP, Kim DW, Bui-Nguyen B, Casali PG, Schöffski P, Aglietta M, Staddon AP, Beppu Y, Le Cesne A, Gelderblom H, Judson IR, Araki N, Ouali M, Marreaud S, Hodge R, Dewji MR, Coens C, Demetri GD, Fletcher CD, Dei Tos AP, Hohenberger P. EORTC Soft Tissue and Bone Sarcoma Group; PALETTE study group (2012) Pazopanib for metastatic soft-tissue sarcoma (PALETTE): a randomised, double-blind, placebo-controlled phase 3 trial. Lancet 379(9829): 1879-1886.

Wells SA, Robinson BG, Gagel RF, Dralle H, Fagin JA, Santoro M, Baudin E, Elisei R, Jarzab B, Vasselli JR, Read J, Langmuir P, Ryan AJ, Schlumberger MJ (2012) Vandetanib in patients with locally advanced or metastatic medullary thyroid cancer: a randomized, double-blind phase III trial. J Clin Oncol 30(2): 134-141.

Yang TS, Oh DY, Guimbaud R, Szanto J, Salek T, Thurzo L, Vieitez JM, Pover GM, Kim TW (2009) Vandetanib plus mFOLFOX6 in patients with advanced colorectal cancer (CRC): a randomized, double-blind, placebocontrolled phase II study. J Clin Oncol 27: 15s 2009 (Suppl; abstract 4084).

Zipes MD, Libby Peter, Bonow RO, Braunwalk E (2005) Braunwald's Heart Disease: A Textbook of Cardiovascular Medicine. 7th edn pp 207-251. Saunders: Philadelphia, PA.

This work is published under the standard license to publish agreement. After 12 months the work will become freely available and the license terms will switch to a Creative Commons AttributionNonCommercial-Share Alike 3.0 Unported License. 